\title{
Ultra-high-speed serial optical communications: Enabling technologies
}

Oxenløwe, Leif Katsuo; Galili, Michael; Mulvad, Hans Christian Hansen; Ji, Hua; Clausen, Anders; Kjær, Rasmus; Jeppesen, Palle

Published in:

International Conference on Photonics in Switching, 2008. PS 2008.

Link to article, DOI:

10.1109/PS.2008.4804262

Publication date:

2008

Document Version

Publisher's PDF, also known as Version of record

Link back to DTU Orbit

Citation (APA):

Oxenløwe, L. K., Galili, M., Mulvad, H. C. H., Ji, H., Clausen, A., Kjær, R., \& Jeppesen, P. (2008). Ultra-highspeed serial optical communications: Enabling technologies. In International Conference on Photonics in Switching, 2008. PS 2008. (pp. 1-2). IEEE. https://doi.org/10.1109/PS.2008.4804262

\section{General rights}

Copyright and moral rights for the publications made accessible in the public portal are retained by the authors and/or other copyright owners and it is a condition of accessing publications that users recognise and abide by the legal requirements associated with these rights.

- Users may download and print one copy of any publication from the public portal for the purpose of private study or research.

- You may not further distribute the material or use it for any profit-making activity or commercial gain

- You may freely distribute the URL identifying the publication in the public portal 


\title{
Ultra-high-speed serial optical communications: enabling technologies
}

\author{
L.K. Oxenløwe, M. Galili, H.C.H. Mulvad, H. Ji, A.T. Clausen, R. Kjær, P. Jeppesen \\ DTU Fotonik, Department of Photonics Engineering, Technical University of Denmark, DTU Building 343, DK-2800 Lyngby \\ leif.oxenlowe@fotonik.dtu.dk
}

\begin{abstract}
This paper will present recently identified and demonstrated key technologies for ultra-high-speed serial communications. Certain key components such as stabilised highly non-linear fibre switches, periodically poled Lithium Niobate devices and semiconductor optical amplifiers will be described with demonstrations of $640 \mathrm{~Gb} / \mathrm{s}$ transmission, clock recovery, demultiplexing, add/drop, wavelength conversion and channel identification. Timing jitter tolerance is addressed through techniques to create flat-top pulses.
\end{abstract}

Keywords: ultra-high-speed, optical signal processing

\section{Introduction}

The single channel bit rate has continuously increased in deployed optical transmission systems and networks, reaching $10-40 \mathrm{~Gb} / \mathrm{s}$ in today's commercially available systems. With the appearance of new technologies for optical transmitters and receivers operating near $100 \mathrm{~Gb} / \mathrm{s}$ [1], ultra fast signal processing becomes increasingly relevant. For ultra-high-speed serial data operating at rates above $100 \mathrm{Gbit} / \mathrm{s}$, signal processing becomes increasingly challenging and only optical signal processing seems possible. For almost twenty years now, optical time division multiplexing (OTDM) has been explored as a possible route to generate high bit rates in the optical domain, but there has hitherto been no market penetration. There are several reasons for this, and apart from market circumstances, we believe the most important one is the lack of good practical solutions for essential functionalities. With the introduction of internet video transmission, the bit rates have exploded and internet exchange office congestion is becoming a real limitation. Therefore there is once again a need for basic research in solutions to congestion problems.

There is currently a great focus on $100 \mathrm{~Gb} / \mathrm{s}$ Ethernet (100 GE), and in 5-10 years from now, in Internet exchange stations one may have several $100 \mathrm{GE}$ lines, which may need to be transmitted to the same destination, and to avoid congestion, it may be beneficial to employ an ultra-fast optical Ethernet multiplexing. This would result in an optical
$1000 \mathrm{GE}$, or 1 Terabit/s Ethernet, $1 \mathrm{TE}$. In fact, at OFC 2008, plenary speaker Bob Metcalfe, inventor of the Ethernet, professed that $1 \mathrm{TE}$ will be needed soon, and that it is essential to conduct fundamental research on new technologies that can carry this burden, since current technologies cannot [2]. Whether 1 TE will be best created serially or in parallel is an open question, but to answer it, it is necessary to conduct research on high-speed serial communications. One great concern with the parallel technologies developed so far is their massive power consumption. Serial solutions combined with circuit switched networks may help to reduce the power consumption.

In any possible future serial-type network scenario one could envisage, a number of essential network functionalities would be needed, including channel identification and add/drop multiplexing. $640 \mathrm{Gbaud}$ symbol rates (pulse rates) has so far been demonstrated as the highest pulse rate carrying data by a few groups worldwide, first in [3] and then most notably in [4], so 1 Tbaud in itself is a challenge.

Here we will present some recent demonstrations of several of the mentioned high-speed functionalities, namely techniques for $640 \mathrm{~Gb} / \mathrm{s}$ demultiplexing, transmission, clock recovery, wavelength conversion and add/drop multiplexing, as well as channel identification and finally touch on the topic of stability and jitter tolerance. We aim at demonstrating that there are solutions for the required functionalities in a high-speed TDM system. Several materials and components will also be shown to be able to operate at high speed. Here we will touch upon highly non-linear bulk-type germanium-doped fibres (HNLF), photonic crystal fibres (PCF) and more compact devices such as periodically poled Lithium Niobate (PPLN), chalcogenide waveguides and semiconductor optical amplifiers (SOAs).

\section{2. $640 \mathrm{~Gb} / \mathrm{s}$ demultiplexing}

Most $640 \mathrm{~Gb} / \mathrm{s}$ demux demonstrations, as the initial one in 1998 [5], involve HNLF. A non-linear optical loop mirror (NOLM) is a popular choice [4-7] due to the inherent
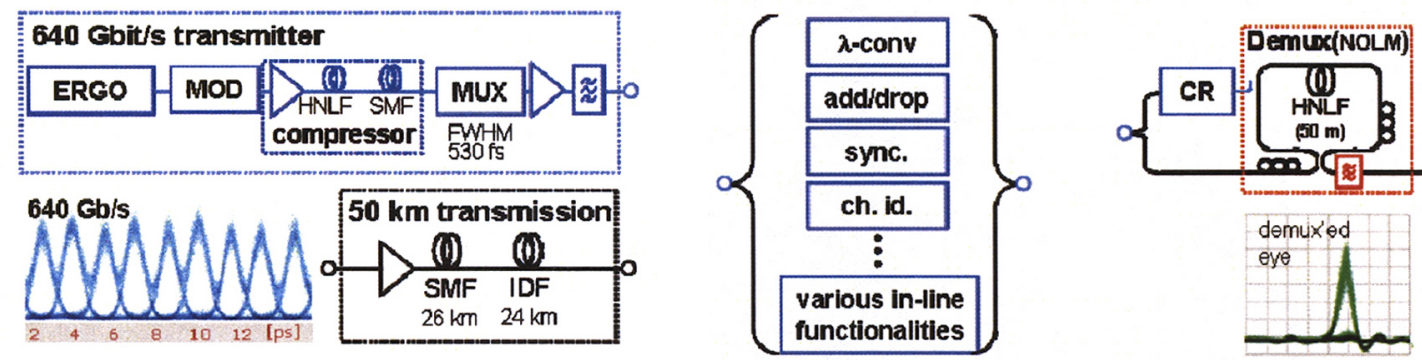

Figure 1. Schematic of $640 \mathrm{~Gb} / \mathrm{s}$ communication system with a lab-type transmitter and receiver. In a more realistic network scenario, the transmitter would be very different to this set-up. Various important in-line functionalities are also sketched 
interferometer arm match of the Sagnac interferometer geometry. HNLF is a mature commercial product from several companies and is very suitable for this application. Other types of fibre have also been used, though only for $160 \mathrm{~Gb} / \mathrm{s}$ demonstrations. This goes for photonic crystal fibre [8] or bismuth-oxide fibre [9]. HNLF has also been used in a Kerr switch at $640 \mathrm{~Gb} / \mathrm{s}$ [10]

Recently, more compact components have been found to be able to demultiplex $640 \mathrm{~Gb} / \mathrm{s}$. An SOA with a detuned filter, filtering out the fast red-shift from a cross-phase modulated signal (filtering-assisted, fa-XPM) was demonstrated at 640 $\mathrm{Gb} / \mathrm{s}$ in [11]. Chalcogenide waveguides have been shown to operate at $160 \mathrm{~Gb} / \mathrm{s}$ [12] and very recently at $640 \mathrm{~Gb} / \mathrm{s}$ [13].

\section{3. $640 \mathrm{~Gb} / \mathrm{s}$ transmission and clock recovery}

Ultra-high-speed clock recovery has proven to be exceptionally challenging, and only very recently was $640 \mathrm{~Gb} / \mathrm{s}$ reached allowing for real transmission demonstrations [14]. In [14], f-a XPM in an SOA was used, as in a previous experiment at $320 \mathrm{~Gb} / \mathrm{s}$ [15]. This was quickly followed by a second $640 \mathrm{~Gb} / \mathrm{s}$ demonstration [16]. In [16-17], a PPLN device was used, relying on the $\chi^{(2)}$ -mediated process of sum-frequency generation, which is truly ultra-fast and not depending on any carrier recovery. With these two techniques, full $640 \mathrm{~Gb} / \mathrm{s}$ transmission systems are now realisable.

Adding a base rate phase mark on one channel and then filter that out to use for clock recovery has also proven viable at $320 \mathrm{~Gb} / \mathrm{s}$ and simultaneously allowing for channel identification [18]. This should scale up to $640 \mathrm{~Gb} / \mathrm{s}$.

\section{4. $640 \mathrm{~Gb} / \mathrm{s}$ wavelength conversion}

Four wave mixing (FWM) in HNLF was used to convert at $640 \mathrm{~Gb} / \mathrm{s}$ from the $C$ to the $L$ band and back again in [19]. The $20 \mathrm{~dB}$ bandwidth of the $640 \mathrm{~Gb} / \mathrm{s}$ data was about $20 \mathrm{~nm}$, so it would be difficult to stay in the $\mathrm{C}$ band when converting with FWM. In [20], Raman-enhanced XPM was used to convert a $16 \mathrm{~nm} 20 \mathrm{~dB}$ bandwidth $640 \mathrm{~Gb} / \mathrm{s}$ data signal to a lower wavelength within the $C$ band. These two demonstrations so far constitute the only reported successful $640 \mathrm{~Gb} / \mathrm{s}$ wavelength conversion experiments, and they both utilise HNLF.

An SOA with fa-XPM has also been shown to operate up to $320 \mathrm{~Gb} / \mathrm{s}$ [21], but due to carrier recovery issues this does not seem set for $640 \mathrm{~Gb} / \mathrm{s}$ just yet.

\section{5. $640 \mathrm{~Gb} / \mathrm{s}$ add/drop multiplexing}

Recently, simultaneous add and drop was demonstrated at $320 \mathrm{~Gb} / \mathrm{s}$ [22], and is now upgraded to $640 \mathrm{~Gb} / \mathrm{s}$ [23].

In [24], $640 \mathrm{~Gb} / \mathrm{s}$ add/drop is performed in a non-linear polarisation-rotating fibre loop. [22-24] use HNLF.

In [9], a $1 \mathrm{~m}$ bismuth oxide fibre is used at $160 \mathrm{~Gb} / \mathrm{s}$. A HNLF-based Kerr switch is used in [25] and a NOLM in [26], both at $160 \mathrm{~Gb} / \mathrm{s}$ with eye characterisation at $320 \mathrm{~Gb} / \mathrm{s}$.

\section{Pulse shaping for increased timing tolerance/stability}

Flat-top pulses have been proven to increase the timing tolerance of high-speed switches and enable retiming. Various approaches have been followed, such as the optical Fourier transform technique [27], using super-structured fibre Bragg gratings with sinc-function spectral shape [28] or using optical differentiation based on detuned long-period gratings for $640 \mathrm{~Gb} / \mathrm{s}$ [29]. To further enhance stability of a fibre switch, polarisation independence can be invoked in a NOLM simply by choosing the right switching power [30]. PM fibres and temperature-stabilisation also help a great deal.

\section{Conclusion}

This paper has provided highlights of ultra-high-speed signal processing demonstrations, in order to demonstrate that solutions exist for many essential $640 \mathrm{~Gb} / \mathrm{s}$ functionalities.

\section{References}

[1] K. Schuh et al, OFC 2007, paper PDP23, 2007

[2] Bob Metcalfe, http://www.ofenfoec.org/conference program/Plenary.aspx

[3] M. Nakazawa et al, Electron. Lett., 36 (24), (2000)

[4] H.G. Weber et al, Electron.Lett., 42 (3), (2006)

[5] M. Nakazawa, et al, Electron. Lett. 34 (9) 1998

[6] H. Sotobayashi et al, OFC 2002, paper WM2,

[7] J. Seoane et al, ECOC 2004, paper We1.5.4

[8] L.K. Oxenløwe et al, ECOC 2003, paper Th2.5.3

[9] J. H. Lee, Optics Express, 13 (18), pp. 6864, 2005.

[10] S. Watanabe et al, ECOC 2004, paper Th4.1.6

[11] E. Tangdiongga et al, PTL 18 (8), (2006)

[12] M.D. Pelusi et al, Photon. Technol. Lett., 19 (2007)

[13] J. Xu et al, to be published

[14] E. Tangdiongga et al, ECOC'07, 2007. paper PD 1.2

[15] L. K. Oxenløwe et al, ECOC'05, paper We3.5.5

[16] L.K. Oxenløwe et al, OFC 2008, paper PDP22

[17] L.K. Oxenløwe et al, Electron. Lett. 44 (2008), p. 370

[18] M. Galili et al, ECOC 2007, paper 5.3.2

[19] H. Sotobayashi et al, OFC 2002, paper WM2

[20] M. Galili et al, OFC 2008, paper OTuD4

[21] Y. Liu et al, OFC 2006, paper PDP28

[22] H. C. Hansen Mulvad et al, OFC 2007, Paper OTul

[23] H. C. Hansen Mulvad et al, to be published

[24] H. C. Hansen Mulvad et al, accepted for ECOC 2008

[25] C. Schubert et al, OFC 2005, Paper OThN2, 2005

[26] E. J. M. Verdurmen, ECOC 1997, vol. 1

[27] L.K. Oxenløwe et al, ECOC 2006, paper We2.3.4

[28] L.K. Oxenløwe et al, OECC 2007 - paper 13B3-4

[29] L. K. Oxenløwe, JSTQE, 14 (3), pp. 566-572, 2008

[30] H.C. Hansen Mulvad et al, OFC 2008, paper OMN3 